\title{
Geophysical Characterization of Disturbances in the Phosphate Series of the OuladAbdoun, Morocco: Relationship with Atlasictectonics
}

\author{
Zerouali E., PhD \\ Cherifien Phosphate Group, Casablanca, Morocco \\ Wafik A., Professor \\ Department of Geology-Faculty of Sciences-Semlalia, \\ Cadi Ayyad-Marrakech University, Marrakech, Morocco \\ Najine A., Professor \\ Faculty of Sciences and Techniques, \\ Department of Earth Sciences, Béni-Mellal, Morocco \\ Radouani F., PhD \\ Cherifien Phosphate Group, Casablanca, Morocco \\ Alaoui M., PhD \\ Faculty of Sciences and Techniques, \\ Department of Earth Sciences, Béni-Mellal, Morocco
}

Housni F.E., Doctor

Southern Region University Center, University of Guadalajara, Mexico

URL:http://dx.doi.org/10.19044/esj.2020.v16n2p49

\begin{abstract}
The sedimentary phosphates series from the Upper Maastricht to the Lutetion of the OuladAbdoun sedimentary basin is almost identical at the basin-scale. It is made up by alternation of either phosphate or non-phosphate sub-horizontal levels. The series was characterized by rhythmic sedimentation under the form of successive elementary sequences. On the other hand, the series of SidiChennaneis distinguished by the presence of local disturbances defined by the miners under the term "dérangements". These "dérangements", which are less frequent at other mining sites (MEA Lahrech, El Hlassa, Point A), are a notable problem during extraction and remain a real obstacle at phosphate mining sites. The morphology of these "dérangements" is almost subcircular to subconical sinkholes and chaotic bodies of anarchical materials. They are fontis type paleokarsts, it is an amalgam of highly altered yellowish brecciated rusty material whose lithological nature reflects that of the surrounding series. They also reflect endokarst siliceous and ferruginous neoformedfacies in the empty spaces of the palaeokarst. The origin of the
\end{abstract}


palaeokarstshasbeen linked to the presence of NE-SW trend faults that have favoured the alteration and dissolution of the gypsum and chalk facies of the Senonian. The regular spatial distribution of these fontisis well related to the regionalAtlasictectonics. This study aims to investigate these problems in its geological aspect, in order to characterize and understand their origin. The purpose of this work is to compare the results obtained by electric tomography, gravimetry and lineament mapping and match them with geological data to draw a meaningful conclusion on the existence of these disturbances and their spatial distribution in relation to tectonic.

Keywords: Phosphate Series, Ouled Abdoun, Disturbance, Tomography, Gravimetry

\section{Introduction}

At the studied area, all the mining sites of the Office Chérifien (OCP) des Phosphates Group have geologically characterized by similar sedimentary phosphate series, with the same age and facies. Nevertheless, the Oulad Abdoun deposit is distinguished by the presence, within the phosphate series, of hard structures qualified as sterile and called "Dérangments" by the miners. These structures, which are not exploitable by the OCP group, interrupt the normal succession of layers in the series and then disturb on a large scale the extraction. In addition to their impact on phosphate's extraction that is serious and costly, problems arise in reserves estimation. It is in this context that a geophysical study is required to unravel the mysteries of these structures.

\section{Presentation of the study area}

The phosphate plateau consists of a set of nested platforms dissected by erosion, each corresponding to the most resistant limestone levels of the sedimentary series. It extends from the Cretaceous to the Eocene (Belfakira, 1980). The altitude of these plateaus varies between $450 \mathrm{~m}$ in the region of Settat and $850 \mathrm{~m}$ near Khouribga. They terminate to the north and south by a relief in "Cuesta" with mounds in front of the line of ribs (Etienne et Guessab, 1975).On the shales and pale quartzites of the Paleozoic which flush out to the north and southwest of the plateau, there is successively: The InfraCenomanian, the Cenomanian, the Turonian, the Senonian, the Maestrichtian and the Eocene. These terrains, overall, are capped by a mass of detrital limestone (Belfakira, 1980). 


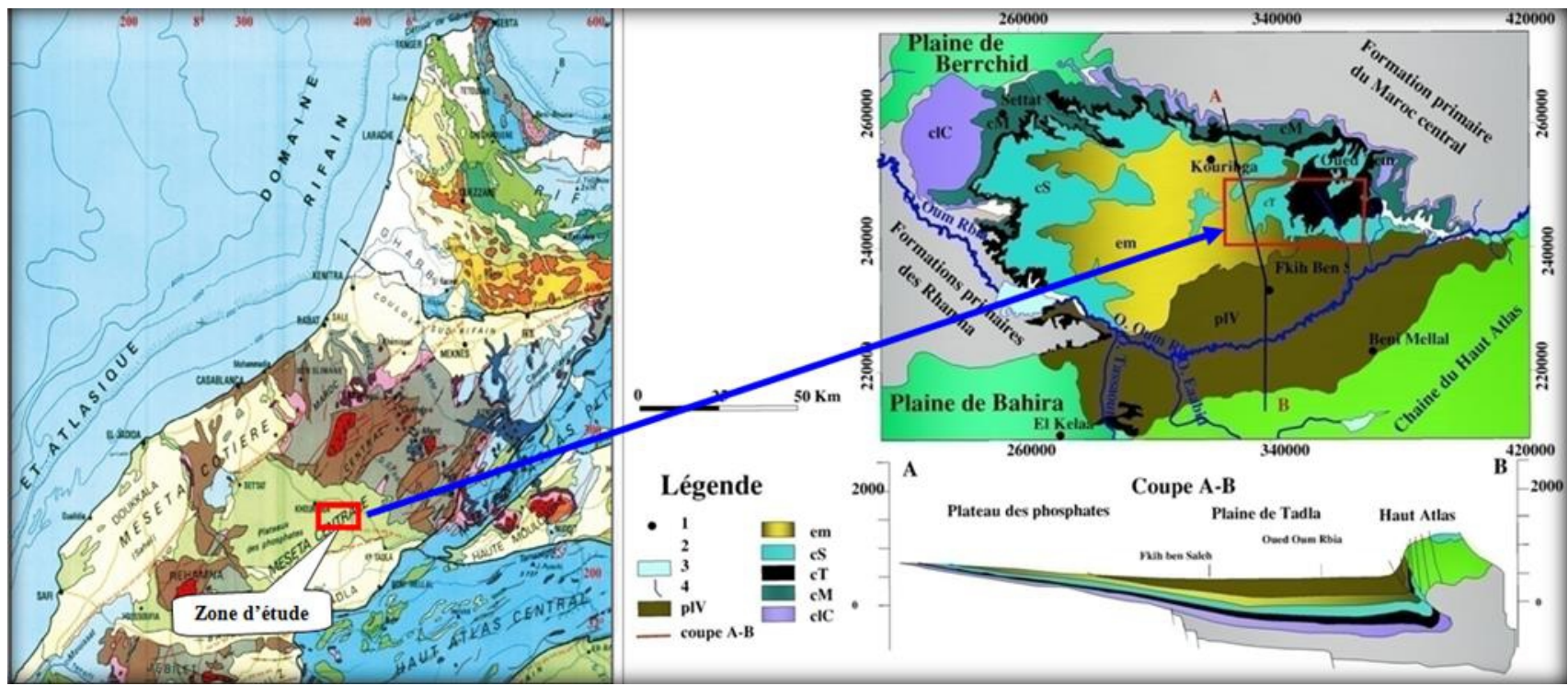

Figure 1 : Location of the study area at the scale of Morocco

Figure 2 :Sketch of the geological map to 1/500000 modified and cross-section on the area of the phosphate plateau and the Tadla plain. 1: main city; 2: Limits of the studied area; 3: Dam; 4: River; pIV: Mio-Plio-Quaternary; em: Middle Eocene; $\mathrm{S}$ : Senonian; cT: Turonian; cM: Cenomanian; cIC: InfraCenomanian. in M. SAADI (completed in 1982)

\section{Description of the phosphate series}

The phosphate series of the OuledAbdoune deposit starts from the Maastrichtian (Boujo, 1976) formed by an alternation of limestone, phosphate marls and sandy phosphates. Then comes the Paleocene made up of movable phosphates and phosphate limestone that end with coprolites limestone with flint nodules. A powerful Eocene formation overcomes the Paleocene formed by alternating levels of soft phosphates, marl-phosphate limestone and flint. The phosphate series ends with a limestone bar containing shells called the upper Eocene "thersity slab" characterized by its resistance to erosion (Choubert, 1949). 


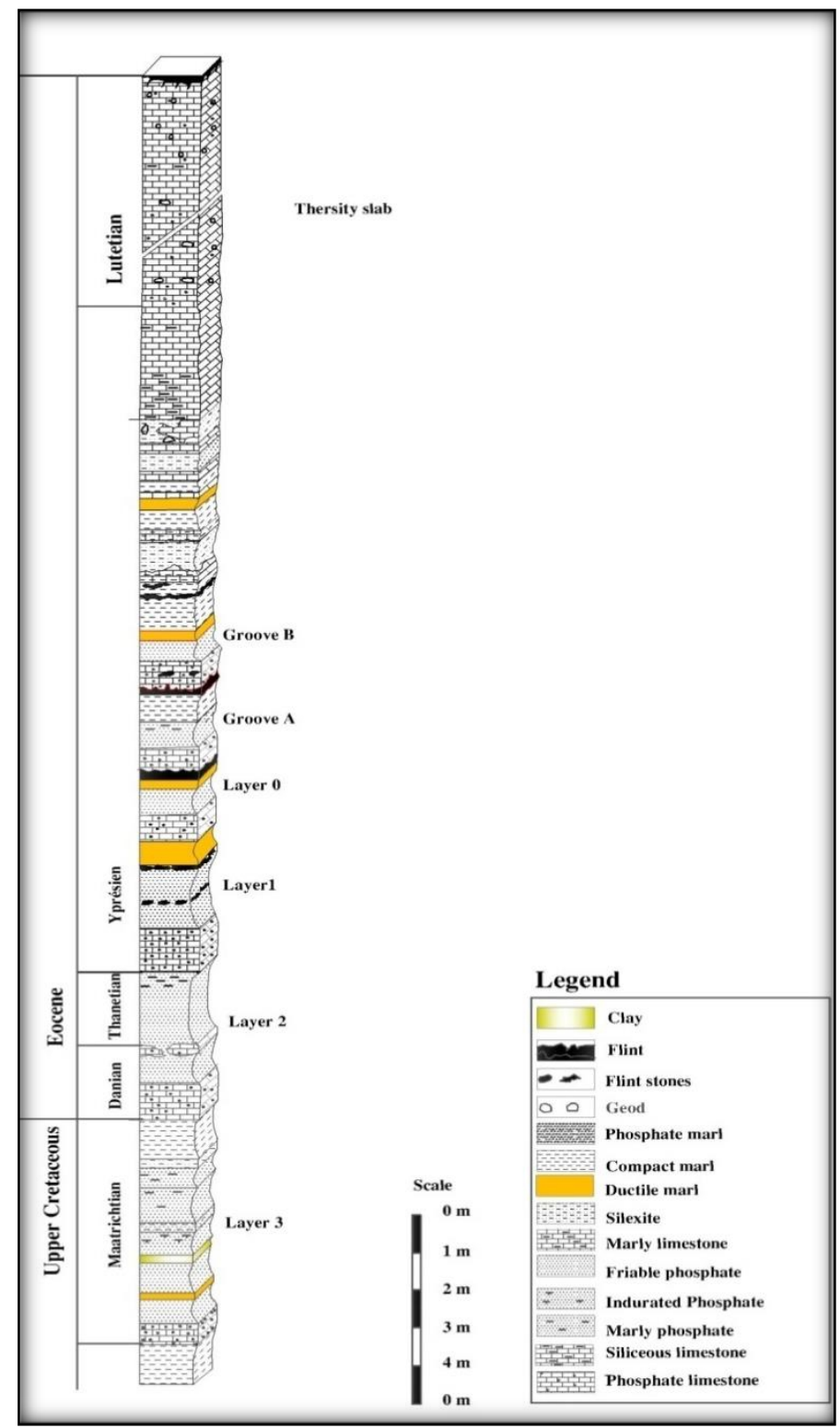

Figure 3: Average lithostratigraphic section of the OuladAbdoune phosphate deposit (OCP internal report)

\section{Geophysicalsurveys:}

\subsection{Tomography}

Data interpretation has been performed using Loke and Barker's (1995) inversion method. The efficiency of this modelling method has been widely proved in many cases of geophysical prospecting studies applied to subsurface surveys. 
This modelling has applied to all tomography profiles made at the studied area. Subsurface models under the form of resistivity sections of the investigated terranes were collected as results. The results were presented in the figures below, showing the data measured as models of the real resistivity of the subsurface obtained after inversion. The first examination of all the gathered sections reveals the existence of significant variations in the resistivity of the subsurface, reflecting its heterogeneity. The established resistivity sections have been divided into two main groups according to their location:

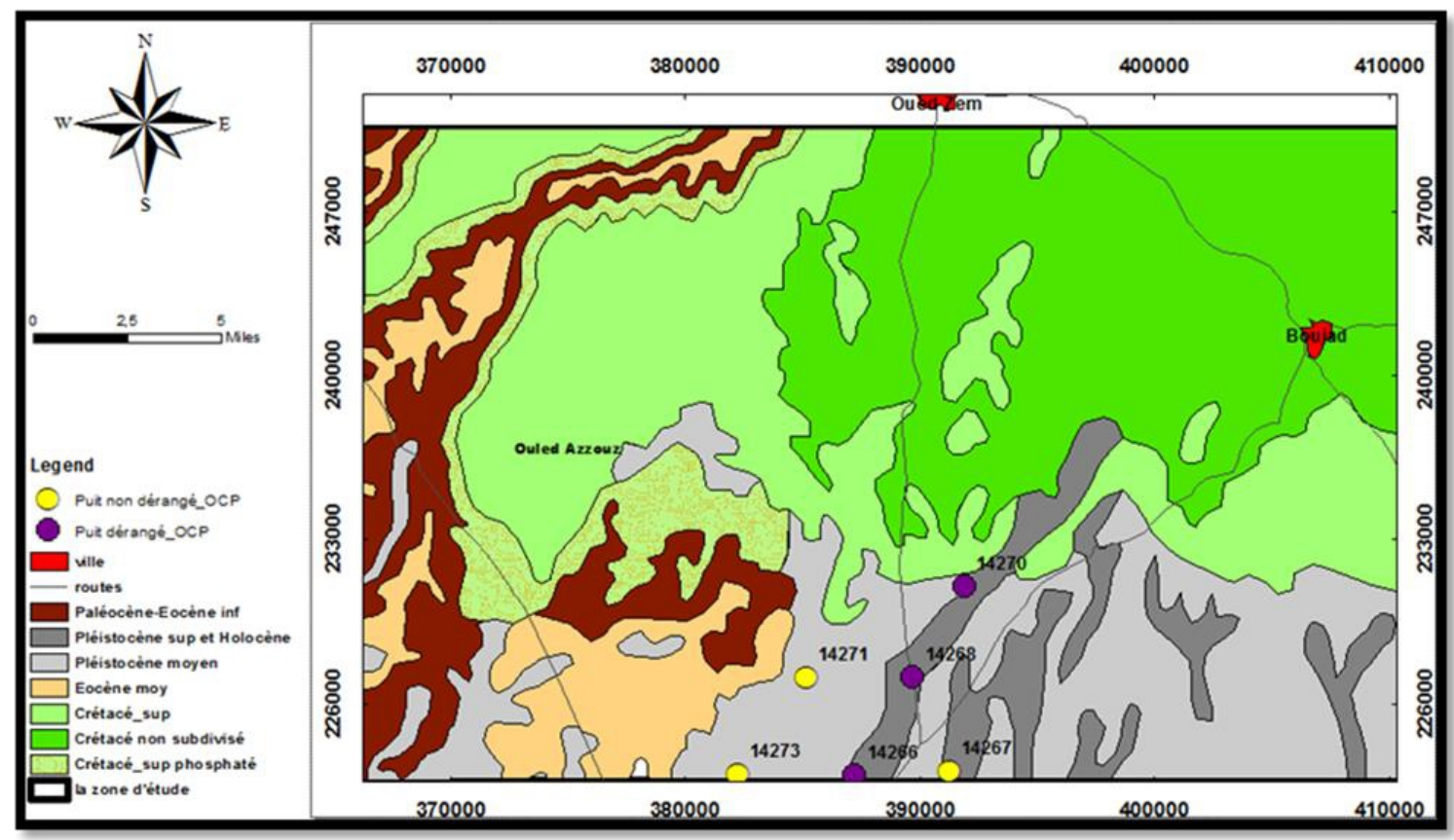

Figure 4: Position of tomographic profiles from OCP wells in the study area

The subsurface resistivity models achieved with three profiles in each of 3 exploration wells $\mathrm{N}^{\circ} 14267, \mathrm{~N}^{\circ} 14271, \mathrm{~N}^{\circ} 14273$ are not affected with any disturbance (internal OCP report) and show a normal succession of sedimentary layers of the undisturbed phosphate series (figures 5-6 and 7). 


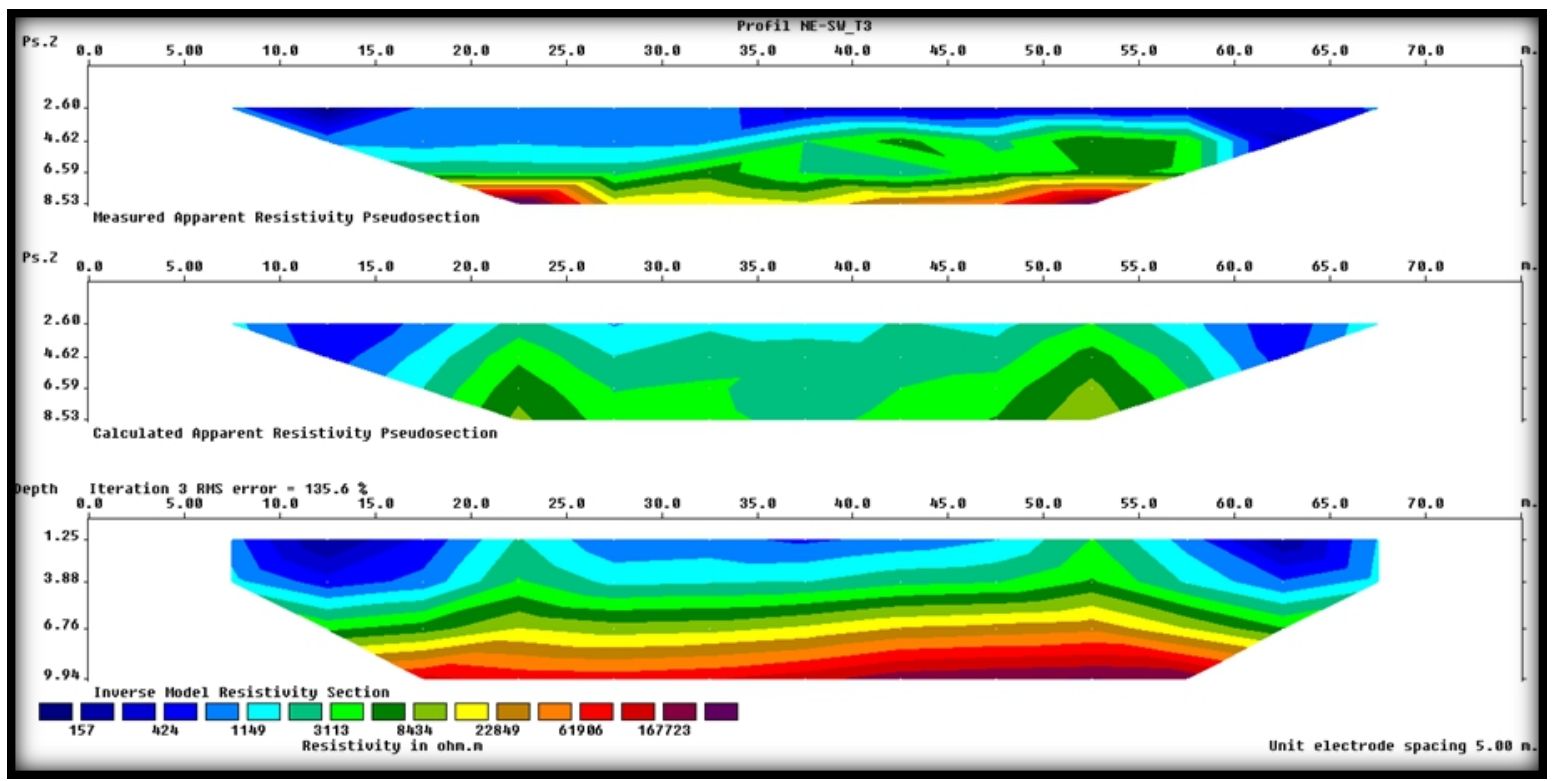

Figure 5 :Tomographic profile performed on the undisturbed wellN 14267

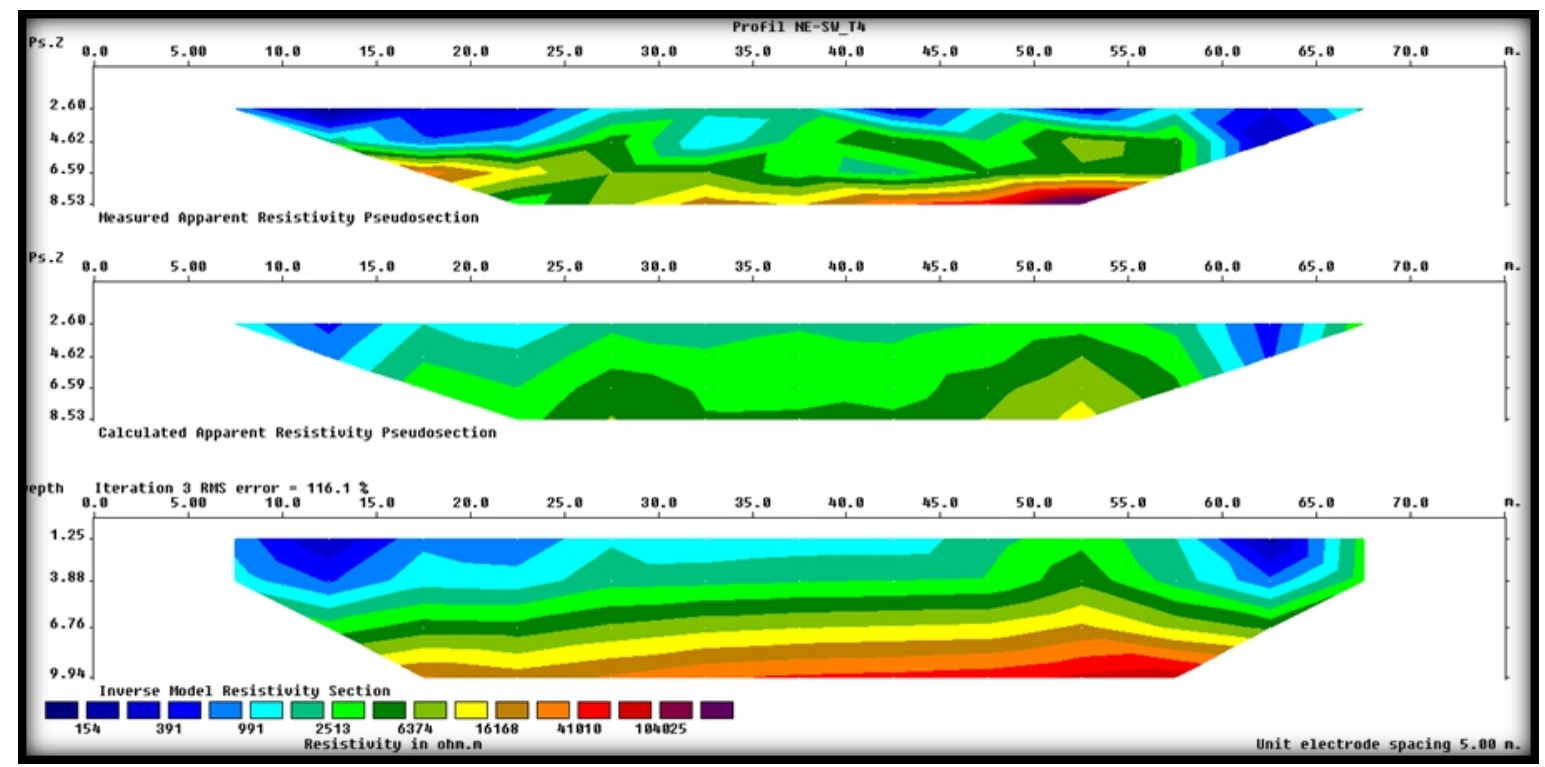

Figure 6 : Tomographic profile performed on the undisturbed wellN ${ }^{\circ} 14271$ 


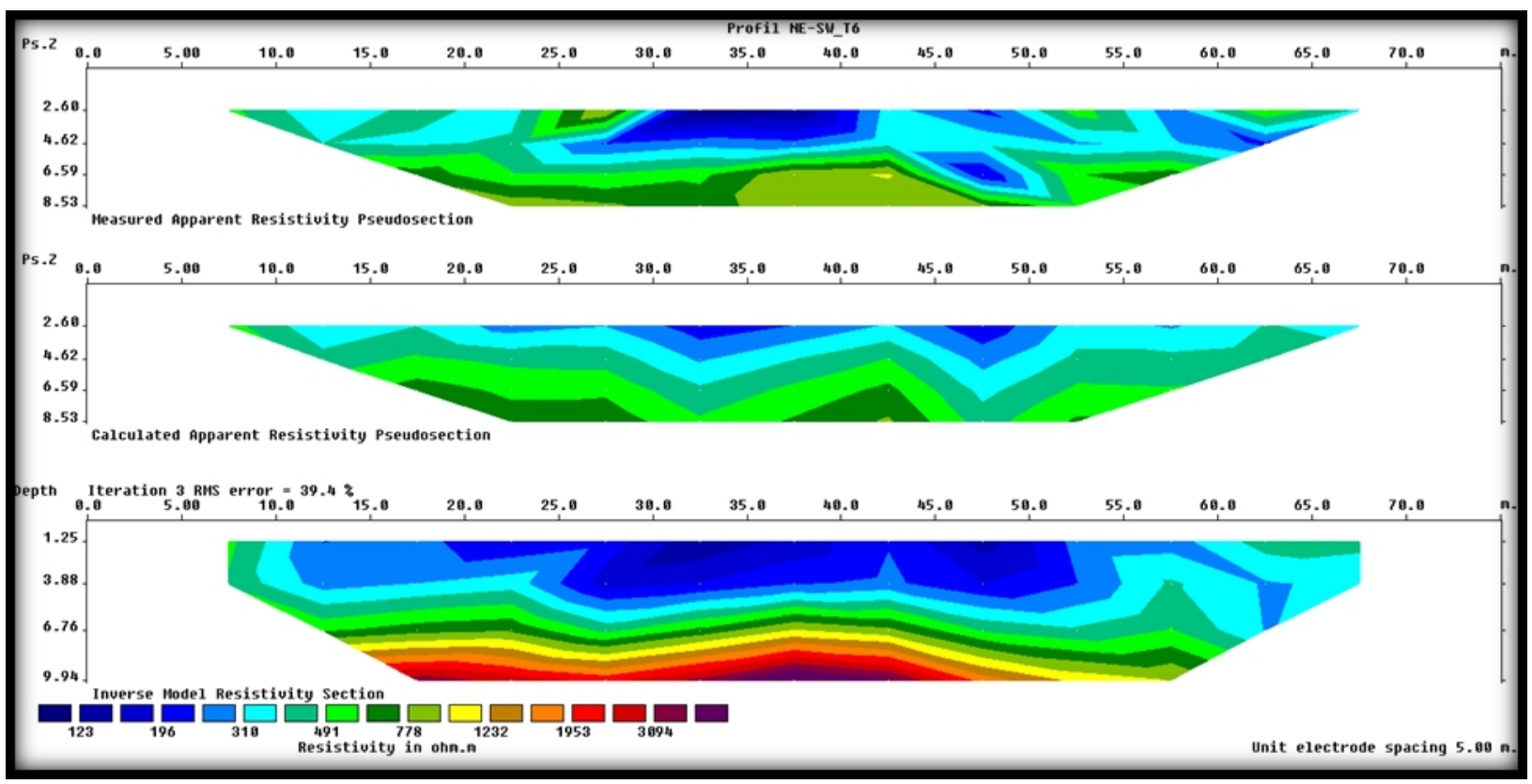

Figure 7 : Tomographic profile performed on the undisturbed wellN ${ }^{\circ} 14273$

\section{b- Tomographic profiles made on disturbed exploration wells:}

On these profiles, the stratigraphic succession is the same as that predicted by the local geology. It should be noted that these profiles were carried out on exploratory wells No. 14266, 14268, 14270 and which have revealed the existence of disturbances in the subsurface Terrans caused by the sterile bodies interrupting the normal succession of the phosphate series. Analysis of the resistivity models described above revealed a resistant anomaly related to slightly conductive to conductive layers with lateral variation in resistivity. The very low resistivity found in some stations (less than $6 \mathrm{Ohm} . \mathrm{m}$ ) is significant alternating of marl-clay and phosphate of the phosphate series. The higher resistivity, evident in the last three profiles, are, on the contrary, characteristic of the very resistant bodies well known in the phosphate series of the Oulad Abdoun sedimentary basin deposit. These sterile bodies or disturbances interrupt the normal succession of the phosphate series in several places. 


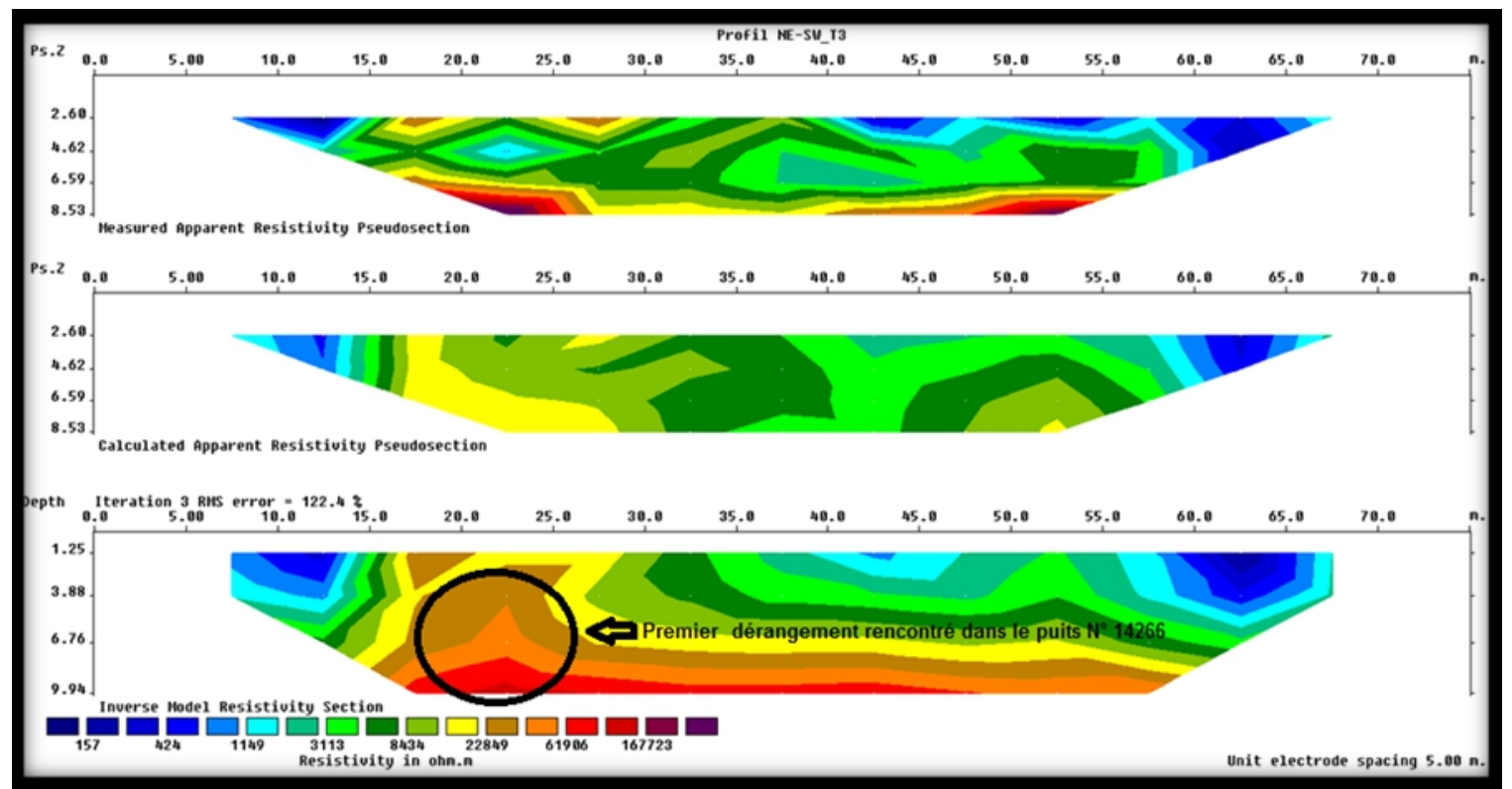

Figure 8 :Tomographic profile performed on the disturbed wellN${ }^{\circ} 14266$

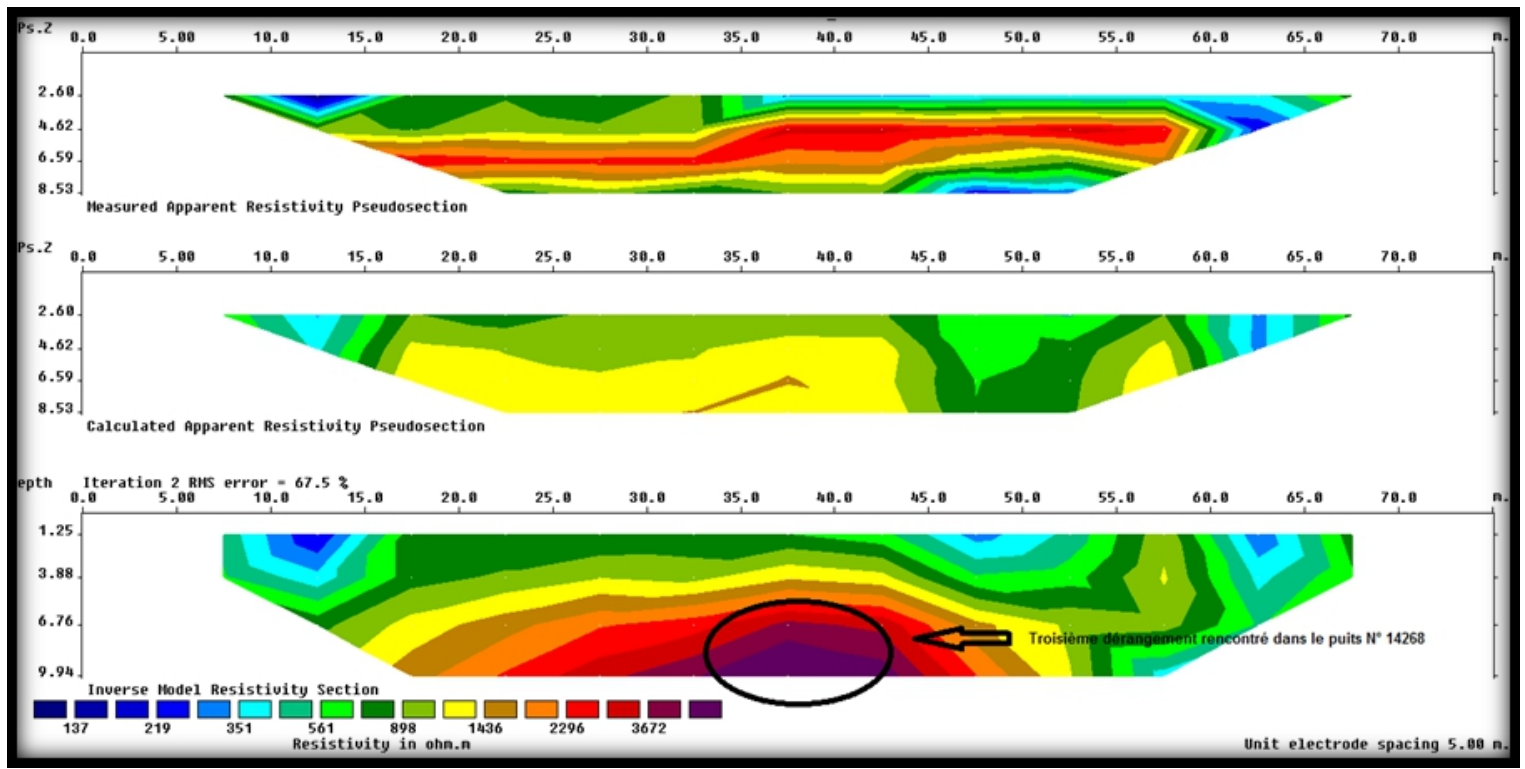

Figure 9: Tomographic profile performed on the disturbed wellN 14268 


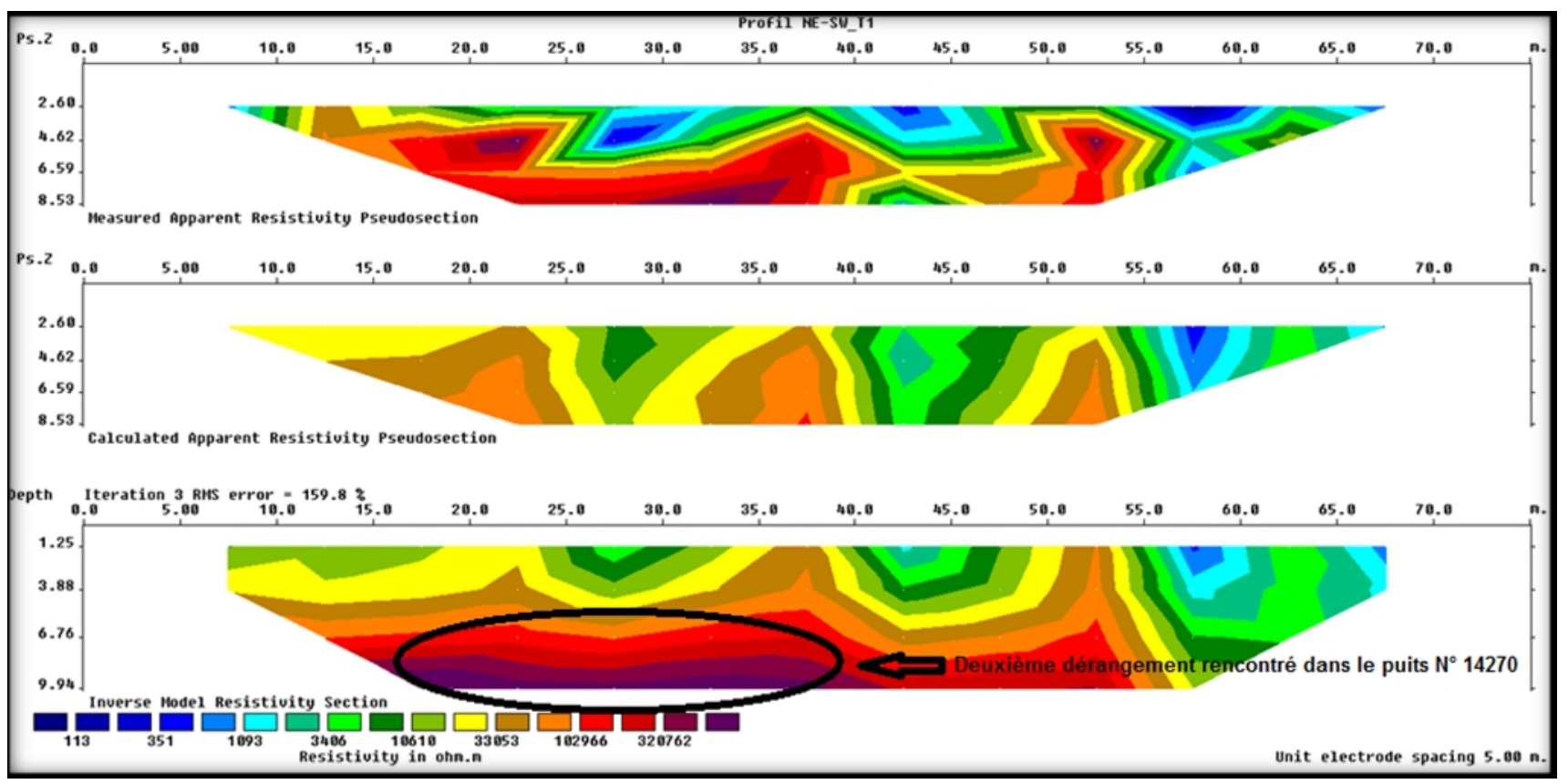

Figure 10 : Tomographic profile performed on the disturbed well ${ }^{\circ} 14270$

\subsection{Gravimetricsurvey recognition \\ Material and method}

According to Newton's Law of Universal Gravitation (Figure 11), any mass around the Earth is subjected to an acceleration g, called gravitational acceleration, which defines the gravity field. Gravimetric consists of measuring this value to deduce the variations in the density of the subsurface.

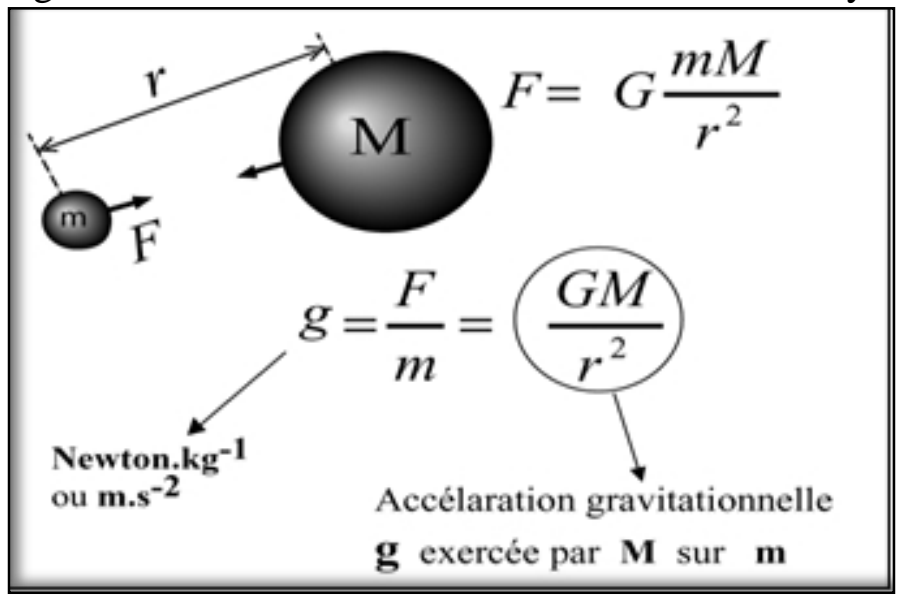

Figure 11: Newton's Law

If the Earth were homogeneous, perfectly round, isolated in space and static, gravity g would have the same value everywhere. Measurements of the 
gravity field on the Earth's surface has shown that this is not the case, because gravity has varied from one point to another.

The causes of these variations are of two types. Some are of nongeological origin, one strives in gravimetric prospecting to eliminate them. Others called geological, are due to the heterogeneities of the subsoil. It is these variations that we seek to highlight and study.

\section{Results}

The examination of the gravimetric map of the Tadla basin presents: from the north towards the south, a decrease in the value of the isostatic anomaly, this variation could be justified by the thickening of the sedimentary series on the High Atlas' boundary.

The treatments employed for the data have facilitated the highlight of the anomalies. In fact, the filtered maps made it possible to analyze in detail the gravimetric signature of the heterogeneities superficial of density.

The figure 12 summarizes the results obtained and indicates that both the anomalies of the vertical gradient and all the lineaments have a global eastnortheast-west-southwest direction; in other words, parallel to the extension of the Tadla basin, except for the southeast sector located within the High Atlas to the south of Beni-Mellal. Moreover, the structural features of the Tadla basin have found whose geometry was shaped by the compression that led to the construction of the surrounding atlasic mountain range.

Geological studies based on exploration wells have shown that the Tadla basin is similar to a Neogene and Quaternary filled furrow composed mainly of materials of the collapsing High Atlas mountain range (Verset, 1988). This sedimentation led to a very heterogeneous sedimentary filling. 


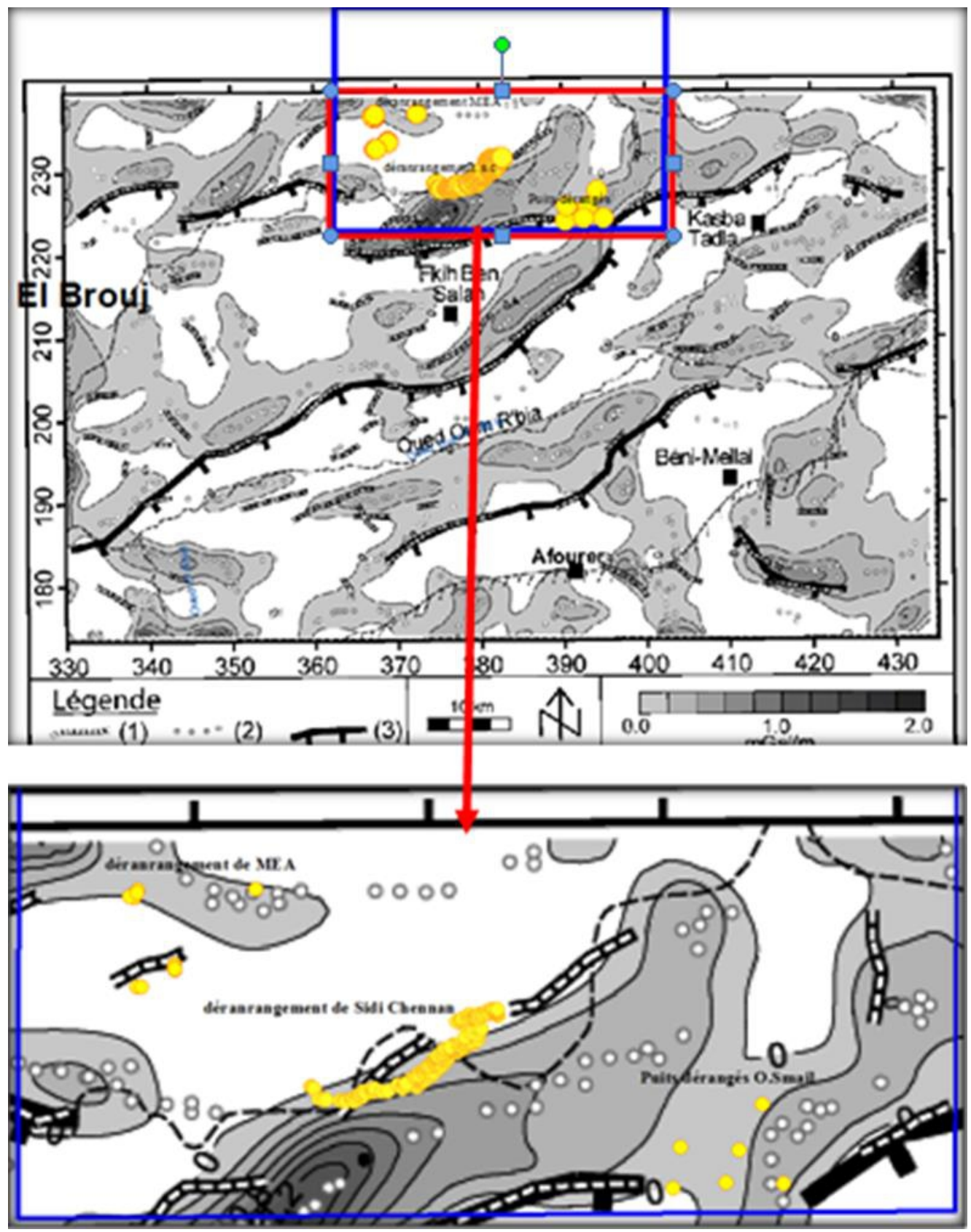

O Dérangementencountered in the MEA, SidiChennan and OuladSmail areas

Figure 12 : Map showing the positive values of the vertical gradient (in gray level) superimposed on the maximum values of the horizontal gradient.1. Maxima of the horizontal gradient values. Maxima of the second derivative. 3. Major fault or flexure interpreted (Van den Bosch, 1981). 
The analysis of the isostatic anomaly map of gravimetric high-gradient and the lineaments that appear from the gravimetric contacts (maximum of the horizontal gradient) revealed some major structures. These are probably faults or flexures that are represented by thick lines with an indication of the direction of subsidence (fig 12).

\section{Discussion}

The projection of the disturbances recorded at the Sidi Chennane, MEA Lahrech and Oulad Smaill mining sites of the phosphate series, in Oulad Abdoun sedimentary basin on the map of positive values of the vertical gradient (in grey level) superimposed on the maximum values of the horizontal gradient values, has allowed us to announce that the distribution of disturbances is not irregular. In fact, this arrangement of structures in the way they are oriented in the map leaves no doubt that their origin is due to regional tectonics with its major northeast-southwest direction faults. The reactivation of these faults has well guided the spatial distribution of these disturbances in the area.

The phosphate series of the two other Moroccan deposits (Guantour, Boucraa) shows no disturbance; phosphate mining began in 1981 and no disturbance has been recorded so far. This confirms the previous idea that the tectonics of the High Atlas mountain range remained the source of these numerous disturbances in the Oulad Abdoun series, and as a result, a slow cadence in the chain of phosphate extraction has observed in this mining site.

\subsection{Lineaments recognition}

\section{Method}

The automatic extraction of lineaments in this study is performed by the LINE module of the Geomatica software. Geomatica's LINE module extracts the linear structures of the digital terrain model image and saves them in ArcGIS vector segment format.

\section{Results}

The lineaments map and wind rose in the figure below shows that the majority of the lines have a NE-SW direction, with other significant lineaments directed N130 - N160 and sometimes-even east- west. By superimposing the fault distribution map with the lineament map, the direction of all disturbances in the study area is generally NE-SW. 


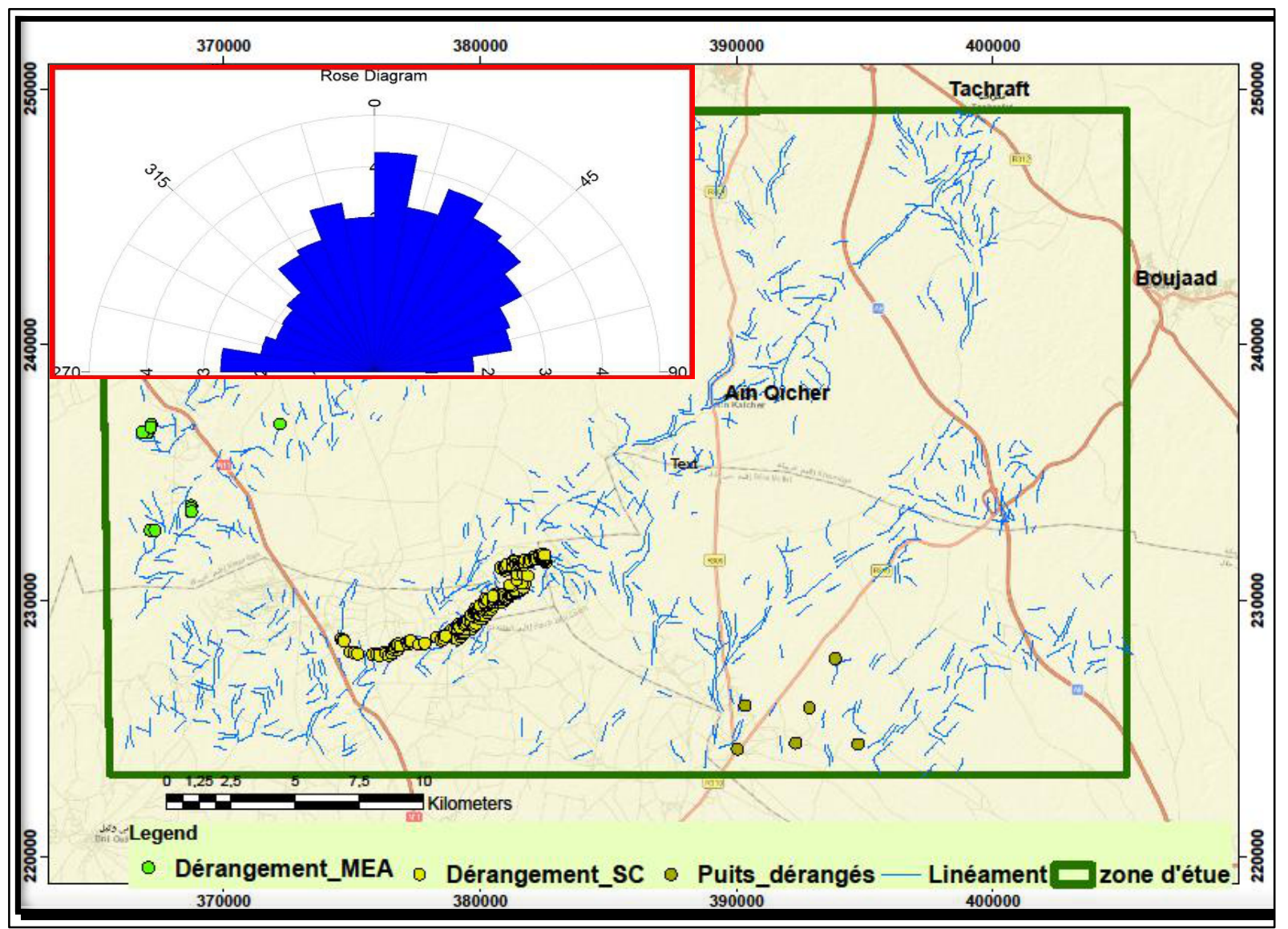

Figure 13:Lineament map with the distribution of the disturbances of the phosphate series of the Ouled Abdoun Basin

\section{Discussion}

This method, like the previous one in terms of results, allowed us to identify the strong link between the direction of the tectonic structures of the region and precisely the NE-SW direction faults and the genesis of these disturbances that are just the local filling of these brittle tectonic structures by the sediment-weathering product of the country-rock. These faults, which are well described by the authors (Saidi and all 2002 ), revealing the period of Atlantic opening, are the result of a Triasico-Jurassic distension NW-SE and NE-SW.

On the ground, this result has been very well confirmed at different stations. In fact, Tachraft 1, Tachraft 2, Ain Qicher North and Ain Qicher South, all these predicted directions, especially N10o to N30o, already mentioned and appeared in the lineament map and leave no ambiguity between the results of the map and the confirmation of the field (fig 14). 

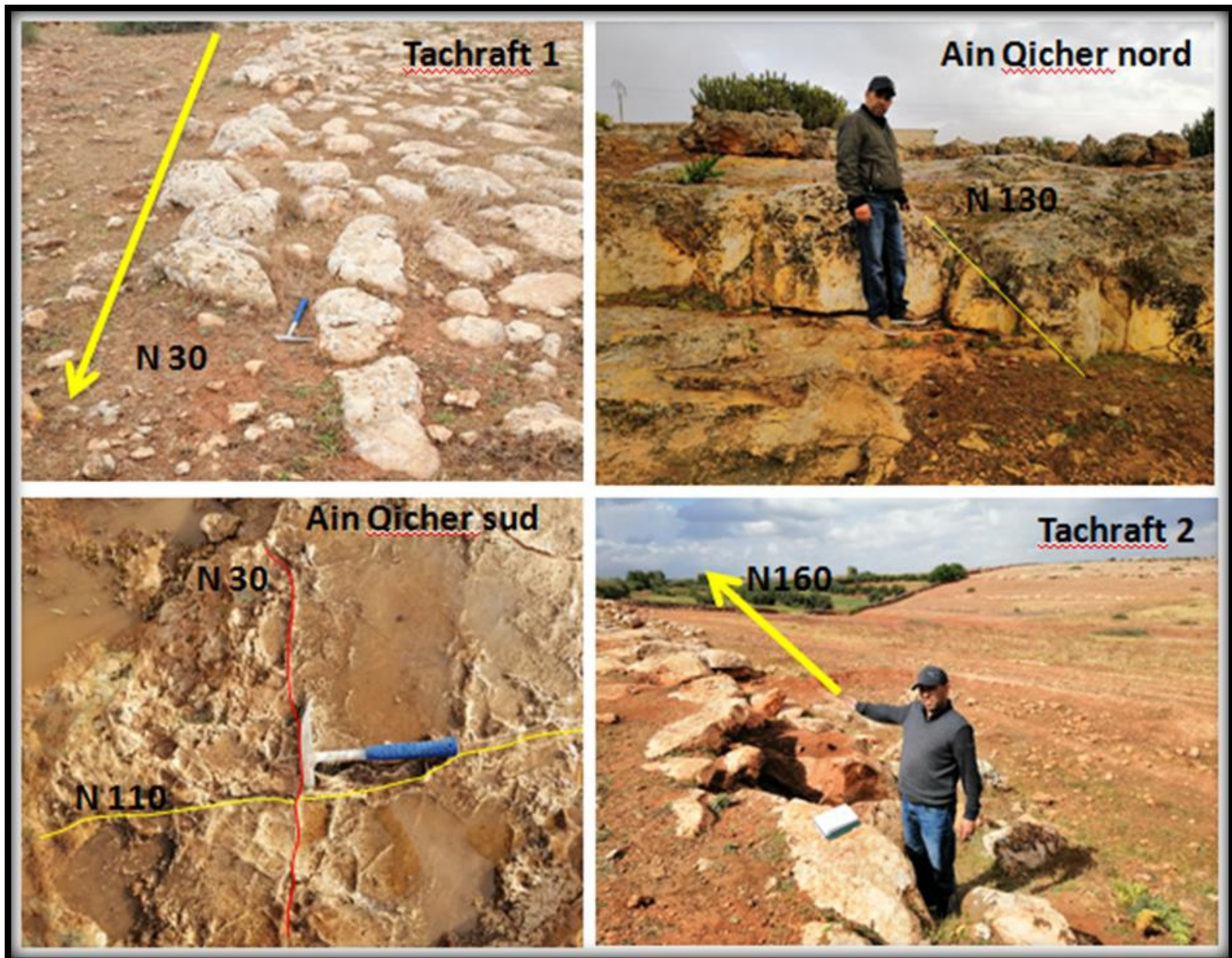

Figure 14 :Images in the field (Oulad smail zone) showing the different directions of fractures and faults.

\section{Conclusion}

The trenches and exploration wells show the presence of the disturbances in the phosphate series of the Oulad Abdoun sedimentary deposit. However, in the studied area, these works have never analyzed the complete vertical and horizontal distribution of these structures. In fact, the exploitation has never reached their roots since they exceed in-depth the lower mined phosphate layer. This lack of information has led us to use electrical geophysical methods for the detection of these disturbances, and the gravimetric map and the lineament map to determine their preferential direction in space.

To do this, tomographic profiles were carried out either on OCP exploration wells having passed through these structures, or on other wells that do not cross them.. The comparison of all these data has enabled us to obtain 
very impressive outcomes; in fact, the phosphate series of the OuladAbdoun deposit is characterized by the presence of structures, called sterile bodies or disturbances -derangements- that are readily detected by gravimetry. This method is easy to apply and can be generalized throughout the basin-scale to map all existing disturbances.

The lineament map is a necessary tool used to understand the spatial distribution general trend of these disturbances, which is generally NE-SW to NNE-SSW.

The gravity map revealed that the disturbances in the studied area and this is the case for the Oulad Abdoun deposit, are strongly linked to regional tectonics, in particular, the NE-SW faults in the Atlas Mountains, which have facilitated the infiltration of the acidic waters; the source of karst formation and their filling by the surrounding material.

\section{References:}

1. Boujo A.,Contribution à l'étude géologique du gisement de phosphates des Ganntour, Maroc occidental, Notes Mém. Serv. Géol. Maroc 262 (1976) (227 p.) ; Sci. Géol. Mém. Strasb. 43 (1976) (227).

2. Choubert G.,SalvanH.M., Essai sur la paléogéographie du Sénonien au Maroc, Notes Mém. Serv. Géol. Maroc 2 (74) (1949) 18-50.

3. Etienne H., GuessabD.(coll.C. Archambault)., 1975. Ressources en eau du Maroc : T.2. Plaines et bassins du Maroc atlantique ; Notes et Mémoires du Service Géologique du Maroc, Rabat, n²31. 299p

4. Belfkira O., 1980. Evolution sédimentologique et géochimique de la série phosphatée du Maastrichtien des Ouled Abdoun (Maroc). Thèse Doct. spec. Géol. Appl., Univ. Grenoble, 164.

5. Loke M.H., and Barker R.D., (1996). Rapid least-square inversion of apparent resistivity pseudo section by a quasi-Newton method; Geophysical Prospecting 44, 131-152.

6. Saidi A., Tahiri A., Aït Brahim L., (2002). États de contraintes et mécanismes d'ouverture et de fermeture des bassins permiens du Maroc hercynien. L'exemple des bassins des Jebilet et des Réhamna. Comptes Rendus Géoscience, Académie des sciences / Éditions scientifiques et médicales Elsevier SAS, 334, 221-226.

7. Van Den J.W., and Bosch H., (1981). Mémoire explicatif de la carte gravimétrique du Maroc (provinces du Nord) au 1/500000. Notes et Mém. Serv. géol. Maroc, 234bis 219p.

8. VersetY., 1988. Mémoire explicatif de la carte géologique (feuille de Kasbat-Tadla). Notes et Mém. Serv. Géol. Maroc, n³40bis, 132p. 